\title{
Use of non-steroidal anti-inflammatory drugs and nutritional supplements in Zimbabwean football
}

\author{
N S Mkumbuzi, ${ }^{1,2}$ BSc (Hons) (Physio); F Kaseke, ${ }^{3}$ MSc (Physio) \\ ${ }^{1}$ Department of Physiology, College of Health Sciences, University of Zimbabwe, Harare, Zimbabwe \\ 2 Zimbabwe Rugby Union, Harare, Zimbabwe \\ ${ }^{3}$ Department of Rehabilitation, College of Health Sciences, University of Zimbabwe, Harare, Zimbabwe
}

Corresponding author: N S Mkumbuzi (nsmkumbuzi@gmail.com)

Background. The use of medications by football players in many populations is known to be high. Data on African players are scarce. Objective. To determine the magnitude of use of non-steroidal anti-inflammatory drugs (NSAIDs) and nutritional supplements by Zimbabwean football players.

Methods. We conducted a cross-sectional study during the 2011/2012 Premier Soccer League football season. A total of 86 players responded to a self-administered questionnaire that assessed self-reported use of NSAIDs and nutritional supplements.

Results. All the participants admitted to taking NSAIDs, with $44 \%$ self-prescribing. Nutritional supplements were taken by $56 \%$ of the respondents. Of these, $21 \%$ took them on a daily basis and $40 \%$ did so without professional advice.

Conclusion. Regular, self-prescribed use of NSAIDs and nutritional supplements is high among Zimbabwean football players.

S Afr J Sports Med 2015;27(1):20-22. DOI:10.7196/SAJSM.577

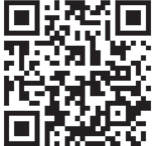

Athletes are usually young individuals in good health, who may use a variety of legal medications and methods to prevent/treat injuries or for competitive edge. This has led to an epidemic of drug use in sport, which is growing in complexity. ${ }^{[1]}$ Often though, most literature and media attention focuses on illegal drugs. ${ }^{[2]}$ However, the use of drugs not banned by the World Anti-Doping Agency should also be considered in light of the ethical and health issues that surround their improper use. Studies have shown that athletes use non-steroidal anti-inflammatory drugs (NSAIDs) and nutritional supplements more than age-matched controls, ${ }^{[1]}$ often in inappropriately high doses, ${ }^{[3]}$ concomitantly and without medical advice. ${ }^{[4]}$ While the major concerns of sporting associations are with the use of illegal drugs and supplements, it is imperative that the magnitude of the use of seemingly harmless drugs be investigated, both to safeguard players' welfare and to help design preventive doping measures. Data on the use of legal drugs and supplements by football players are few and far between, and on African players fewer still..$^{[5]}$ The objective of this study was to quantify the magnitude of the use of NSAIDs and nutritional supplements by professional Zimbabwean football players.

\section{Methods}

During the latter half of the football season, registered football players from 11 of the 16 teams in the Premier Soccer League (PSL) during the 2011/2012 football season were approached via their club management to participate in the study. Questionnaires were taken to their various training stadia during training and distributed at the end of a training session for completion in the players' own time, should they consent to participate in the study. This questionnaire was adapted for contextual validity from those validated by experts and used in previous studies. ${ }^{[5,6]}$ The questionnaires were anonymous and did not contain any identification information.
Permission was obtained from the Zimbabwe Football Association (ZIFA), and the administrative body for the PSL. Ethical approval to conduct this study was obtained from the Institutional Review Board at the University of Zimbabwe, College of Health Sciences, protocol number JREC/150/11.

Continuous variables are presented as means and standard deviations (SDs), and shown as frequencies and percentages.

Results

Of the 400 questionnaires given out, 86 (22\%) were completed and returned. All the participants in this study were male, with a mean (SD) age of 23 (2) years (range 17 - 30). The majority were single (51\%) and had a secondary school education (Table 1 ).

A large proportion of the players ( $83 \%$ ) had been playing football for $>6$ years at the time of data collection (Table 2). More than half of the players trained for $\sim 3$ - 5 hours/day and for 3 - 5 days/week (52\% and $87 \%$, respectively), and this training was related to league games and championship commitments.

Over half of the respondents (56\%) admitted to current use of nutritional supplements, with less than half of these (21\%) taking them daily (Table 3). Vitamin supplements were the major form of supplementation taken (20\%), closely followed by mineral supplements (17\%). The main reason for taking these supplements is unknown, as almost half of the respondents (43\%) did not state the reason. Of those that did, they took dietary supplements to build muscle bulk (15\%), maintain general health (14\%) and for other reasons such as luck. Most of these supplements were taken without expert advice (40\%). Medical doctors were the main source of information and advice on nutritional supplements (27\%). Only one respondent received advice from a nutritionist before taking nutritional supplements, while a number of players sought advice from a traditional healer or other professionals (15\%). 
All participants admitted to taking at least one NSAID at the time of the study (Table 4). Most of these NSAIDs were self-prescribed (44\%). Medical doctors were consulted less for advice and information on NSAIDs than they were consulted for advice on nutritional supplements ( $4 \%$ v. $2 \%$, respectively).

\section{Discussion}

The response rate was $22 \%$, which is typical in this type of population, as football players are difficult to enrol in a large cohort unless at major

\section{Table 1. Demographic data, $\boldsymbol{n}$ (\%)}

\begin{tabular}{ll}
\hline Age (years) & $14(16)$ \\
$15-19$ & $42(49)$ \\
$20-24$ & $27(32)$ \\
$25-29$ & \\
Marital status & $37(43)$ \\
Married/cohabiting & $1(1)$ \\
Divorced/widowed & $44(51)$ \\
Single & \\
Educational status & $3(4)$ \\
Primary & $74(86)$ \\
Secondary & $7(8)$ \\
Tertiary & \\
Position of play & $16(19)$ \\
Goalkeeper & $21(24)$ \\
Defender & $30(35)$ \\
Midfielder & $17(20)$ \\
Striker &
\end{tabular}

Table 2. Length of football career and duration of training sessions, $n(\%)$

Length of football career (years)

$\leq 2$

$3-5$

$\geq 6$

Number of weekly training sessions (days/week)

$\begin{array}{ll}\leq 2 & 0(0) \\ 3-5 & 75(87) \\ \geq 6 & 7(8) \\ \text { Duration of daily training } & \\ \text { essions (hours) } & \\ 0-2 & 2(2) \\ 3-5 & 45(52) \\ \geq 6 & 37(43)\end{array}$

tournaments. Additionally, the study sought information on a somewhat sensitive subject and athletes are generally reluctant to discuss their personal drug habits. ${ }^{[6]}$ The proportion of missing information in our survey was also a testament to this observation (Tables 1 - 4), as is the fact that this response rate is marginally less than that obtained by other authors on the same subject, who interviewed team physicians instead of the players. ${ }^{[2]}$ However, Huang et al..$^{[7]}$ obtained response rates of $94 \%$ and $98 \%$ in athlete interviews during the Atlanta and Sydney Olympic Games, respectively, while Taioli ${ }^{[8]}$ obtained $95 \%$ in a survey of Italian football players. Overall, the response rate in the present study, though low, was considered satisfactory because the results obtained from this study were similar to those from previous studies on the same subject, and the conclusions drawn from these results reflect the same trends as those observed by other authors globally. ${ }^{[2,6-8]}$ This is a good indication that a representative sample was obtained in this study.

Our survey indicated a very high intake of NSAIDs, with $100 \%$ of the respondents reporting intake of an NSAID at the time of data collection. These results are similar to those obtained by other authors in similar

\section{Table 3. Use of nutritional supplements, $\boldsymbol{n}$ (\%)}

Current use of nutritional supplements $(N=86)$

Yes

No

Types of nutritional supplements $(n=48)$

Herbal

Mineral

Protein powders

Vitamin

Multiple

Frequency of use of nutritional supplements $(n=48)$

Never

Daily

Weekly

Twice/week

Monthly

Not sure

Reasons for use of nutritional supplements $(n=48)$

No response

To boost immunity

To enhance performance

To prevent injuries

To augment diet

To build muscle bulk

To maintain general health

Other (e.g. luck, improved power)

Sources of advice on use of nutritional supplements $(n=48)$

Self

Physiotherapist

Medical doctor

Nutritionist/dietician

Fitness trainer

Other (traditional healer, family member, fellow player, coach)

$7(15)$ 


\begin{tabular}{ll} 
Table 4. Use of NSAIDs $(\mathbf{N}=\mathbf{8 6}), \boldsymbol{n}(\%)$ \\
\hline $\begin{array}{l}\text { Frequency of use of NSAIDs } \\
\text { Never }\end{array}$ & $0(0)$ \\
Daily & $10(12)$ \\
Weekly & $9(11)$ \\
Twice/week & $0(0)$ \\
Monthly & $5(6)$ \\
Rarely & $37(43)$ \\
Sources of information and & \\
advice on NSAIDs & \\
Self & $38(44)$ \\
Physiotherapist & $15(17)$ \\
Fitness trainer & $17(20)$ \\
Medical doctor & $3(4)$ \\
Fellow player & $8(9)$ \\
Other & $5(6)$
\end{tabular}

cohorts. Holmes et al. ${ }^{[3]}$ demonstrated a $96 \%$ consumption rate in collegiate football players, $93 \%$ of Italian footballers were found to be taking NSAIDs ${ }^{[7]}$ and $100 \%$ of gymnasts at the Sydney 2000 Olympic Games were found to be taking NSAIDs. ${ }^{[8]}$ In these studies, $50 \%$, $22 \%$ and $100 \%$, respectively, of these athletes took NSAIDs daily, compared with $12 \%$ in the present study; however, our results represent a higher NSAID intake than observed during various Fédération Internationale de Football Association (FIFA) World Cup tournaments, where about $40 \%$ of football players used NSAIDs. ${ }^{[9]}$ At these tournaments, however, the consumption of NSAIDs far outweighed the injury rate. This liberal use of NSAIDs raises misgivings of whether they are being used solely for therapeutic purposes or whether athletes have discovered their ergogenic aid. This theory is supported by data from other studies, which show that athletes are using NSAIDs for 'prophylactic pain management. ${ }^{[9]}$ Some use NSAIDs for treatment of injuries, probably because they do not take time off to rehabilitate minor injuries. ${ }^{[1,10]}$ The latter may also explain the high prevalence of use of NSAIDs in our sample, as the majority of the participants had intense training schedules. This ample use of NSAIDs, often without medical advice, reflects that footballers may be unaware of the cumulative adverse effects of NSAIDs on the various body systems, ${ }^{[10]}$ and may have developed these drug habits from early adolescence, considering that the majority of these participants have been playing football from an early age.
In this study, over half of the football players (56\%) took nutritional supplements. Vitamin supplements represented the majority of the supplements taken (20\%) and were taken daily by $\sim 1 / 5$ players. This is a lot less than the $82 \%$ obtained by Taioli ${ }^{[8]}$ among Italian football players, and that observed by Waddington et al. ${ }^{[6]}$ in English football players (58\%). Vitamins were also the most common form of supplementation (41\%) taken by football players during the 2006 FIFA World Cup. ${ }^{[2]}$ In comparison, across sporting disciplines, the use of nutritional supplements is generally upward of $60 \%{ }^{[2,8,9]}$ It is noteworthy, though, that for reasons unknown, African athletes report lower nutritional supplement use than their European and American counterparts, especially in ball sports such as football. ${ }^{[9]}$ Nutritional supplements are not necessary in athletes who are generally healthy by all standards. However, aggressive advertising and endorsements by supplement manufacturers have led to a high use of supplements in highly active individuals, as they purport to aid recovery and assist with altering body composition favourably. ${ }^{[7]}$ Data to support these assertions are equivocal. ${ }^{[1]}$ This uncertainty is even more pertinent in light of the fact that $40 \%$ of our participants were found to be taking dietary supplements at their own discretion and without professional advice. This trend exists in athletes from other populations, who have a tendency not to consult club medical personnel before taking supplementation. ${ }^{[6,10]}$ This trend to self-medicate is worrisome, especially to the $9 \%$ of the participants who reported taking protein powders that may contain creatine. Creatine and other amino acid preparations, if improperly dosed, may have deleterious effects on vital organs. ${ }^{[6]}$ In addition to the harmful effects that these supplements may have on the body, the risk of crosscontamination with banned substances during manufacture exists, as the manufacture of supplements is not strictly regulated. This, plus inadequate product labelling, may lead to an inadvertent positive dope test. ${ }^{[12]}$ Interestingly, a considerable proportion of our respondents (15\%) consulted a traditional healer for supplements, presumably herbal. This is not surprising in the African setting, where the game of football is fraught with rituals, and the use of juju (traditional medicine) for luck and victory is rife. ${ }^{[13]}$ However, as the active ingredients of most of these preparations are unknown, the possibility of accidental ingestion of a banned substance also exists.

\section{Study limitations}

The data were collected at a single time point, from the footballers' perspective. Drug use frequency may fluctuate during the season and is subject to social and recall bias. Future studies may explore this further over a whole season more objectively, e.g. using blood tests.

\section{Conclusion}

The use of NSAIDs and nutritional supplements was high in these Zimbabwean footballers, but lower than in other similar populations. The major concern is that these medications are taken without professional advice or supervision. In addition to providing information on illicit drugs, information on the effects of permitted drugs such as NSAIDs should be disseminated to athletes, as should the risk of unintentional doping with unchecked use of nutritional supplements.

\section{References}

1. Alaranta A, Alaranta H, Helenius I. Use of prescription drugs in athletes. Sports Med 2008;38(6):449-463. [http://10.2165/00007256-200838060-00002]

2. Tscholl P, Junge A, Dvorak J. The use of medication and nutritional supplements during FIFA World Cups 2002 and 2006. Br J Sports Med 2008;42(9):725-730. [http://10.1136/bjsm.2007.045187]

3. Holmes N, Cronholm PF, Duffy AJ III, et al. Nonsteroida anti-inflammatory drug use in collegiate football players. Clin J Sport Med 2013;23(4):283-286. [http://10.1097/ JSM.0b013e318286dofa]

4. Warner DC, Schnepf G, Barrett MS, et al. Prevalence, attitudes, and behaviors related to the use of nonsteroidal anti-inflammatory drugs (NSAIDs) in student athletes. J Adolesc Health 2002;30(3):150-153. [http://10.1016/S1054-139X(01)00325-1]

5. Ama PFM, Betnga B, Ama Moor VJ, et al. Football and doping: Study of African amateur footballers. Br J Sports Med 2003;37(4):307-310. [http://10.1136/bjsm.37.4.307]

6. Waddington I, Malcolm D, Roderick M, et al. Drug use in English professional football. Br J Sports Med 2005;39(4):e18. [http://10.1136/bjsm.2004.012468]

7. Huang S, Johnson K, Pipe AL. The use of dietary supplements and medications by Canadian athletes at the Atlanta and Sydney Olympic Games. Clin J Sport Med 2006;16(1):27-33

8. Taioli E. Use of permitted drugs in Italian professional soccer players. Br J Sports Med 2007;41(7):439-441. [http://10.1136/bjsm.2006.034405]

9. Tscholl P, Alonso JM, Dollé G, Junge A, Dvorak J. The use of drugs and nutritional supplements in top-level track and field athletes. Am J Sports Med 2009;38:1. [h ttp://10.1177/0363546509344071]

10. Gorski T, Cadore EL, Pinto SS, et al. Use of NSAIDs in tri-athletes: Prevalence, level of awareness and reasons for use. Br J Sports Med 2011;45(2):85-90. [http://10.1136/ bjsm.2009.062166]

11. Hespel P, Maughan RJ, Greenhaff PL. Dietary supplements for football. J Sports Sci 2006;24(7):749761. [http://dx.doi.org/10.1080/02640410500482974]

12. Van der Merwe PJ, Grobbelaar E. Unintentional doping through the use of contaminated nutritional supplements. S Afr Med J 2005;95(7):510-511.

13. Chavunduka GL. Juju and drugs in sports: Myth or reality? Sports, Juju, and Human Factor Development 2006;3:74 